\title{
Variation of Input-Output Properties along the Somatodendritic Axis of Pyramidal Neurons
}

\author{
Hysell Oviedo and Alex D. Reyes \\ Center for Neural Science, New York University, New York, New York 10003
}

The firing evoked by injection of simulated barrages of EPSCs into the proximal dendrite of layer 5 pyramidal neurons is greater than when comparable inputs are injected into the soma. This boosting is mediated by dendritic $\mathrm{Na}^{+}$conductances. However, the presence of other active conductances in the dendrites, some of which are nonuniformly distributed, suggests that the degree of boosting may differ along the somatodendritic axis. Here, we injected EPSC barrages at the soma and at the proximal, middle, and distal segments of the apical dendrite and measured boosting of subthreshold and suprathreshold responses. We found that although boosting was maintained throughout the apical dendrite, the degree of boosting changed nonmonotonically with distance from the soma. Boosting dipped in the middle dendritic segments as a result of the deactivation of the hyperpolarization-activated cation current, $I_{\mathrm{h}}$, but increased in the distal dendrites as a result of the activation of $\mathrm{Ca}^{2+}$ conductances. In the distal dendrites, EPSC barrages evoked repetitive bursts of action potentials, and the bursting pattern changed systematically with the magnitude of the input barrages. The quantitative changes in boosting along the somatodendritic axis suggest that inputs from different classes of presynaptic cells are weighted differently, depending on the location of the synaptic contacts. Moreover, the tight coupling between burst characteristics and stimulus parameters indicate that the distal dendrites can support a coding scheme that is different from that at sites closer to the soma, consistent with the notion of a separate dendritic integration site.

Key words: burst; dendrite; pyramidal; variability; dynamic clamp; boosting

\section{Introduction}

The presence of voltage- and time-dependent conductances in the dendrites greatly enhances the computational abilities of neurons. These conductances boost stimulus-evoked EPSPs (Schiller et al., 1997) as well as inputs that mimic EPSP barrages from a large population of presynaptic cells (Oviedo and Reyes, 2002). In addition, the active conductances may act in concert to compartmentalize synaptic inputs to allow independent computations at different dendritic sites (Mel et al., 1998; Häusser et al., 2001; Gabbiani et al., 2002).

Previously, we showed that barrages of EPSP-like inputs evoked greater firing when injected into the proximal dendrites of pyramidal neurons than when injected into the soma (Oviedo and Reyes, 2002). This boosting of inputs was mediated by the activation of $\mathrm{Na}^{+}$conductances. However, there are other conductances that may affect the degree of boosting (Schiller et al., 1997; Bekkers, 2000; Williams and Stuart, 2000) (for review, see Reyes, 2001; Williams and Stuart, 2003). The hyperpolarizationactivated cation current $\left(I_{\mathrm{h}}\right)$ increases toward the apical tuft. This current increases the membrane conductance so that single

Received July 2, 2004; revised April 11, 2005; accepted April 12, 2005

This work was supported by National Science Foundation Grant IBN-0079619 (A.D.R.), by National Institutes of Health (NIH) Grants DC005787-01A1, NEI-13145, and NS41091 (A.D.R.), and by an NIH National Research Service Award (H.O.). We thank W. Bair, F. Chance, and T. Lewis for valuable comments on this manuscript and A. Kohn for comments on a previous version of this manuscript.

Correspondence should be addressed to Hysell Oviedo, Cold Spring Harbor Laboratory, 1 Bungtown Road, Cold Spring Harbor, NY 11724. E-mail: oviedo@cshl.edu.

DOI:10.1523/JNEUROSCI.0562-05.2005

Copyright $\odot 2005$ Society for Neuroscience $\quad$ 0270-6474/05/254985-11\$15.00/0
EPSPs propagating toward the soma are attenuated more than expected for a passive cable (Stuart and Spruston, 1998; Berger et al., 2001). In addition, $\mathrm{Ca}^{2+}$ channels in the distal dendrites evoke regenerative processes that can lead to bursting and plateau potentials (Stuart et al., 1997; Larkum et al., 2001; Oakley et al., 2001; Larkum and Zhu, 2002). The fact that $I_{\mathrm{h}}$ increases along the somatodendritic axis coupled with the prevalence of $\mathrm{Ca}^{2+}$ spikes in the distal dendrites indicates that the degree of boosting is likely to change with distance from the soma.

Here, we examine how input-output properties vary along the somatodendritic axis of layer 5 pyramidal neurons. First, we document changes in boosting when brief subthreshold depolarization (as would occur with single EPSPs) (Magee, 1999; Williams and Stuart, 2002) and sustained or suprathreshold depolarization (as would occur during EPSP barrages from many presynaptic inputs) (Oviedo and Reyes, 2002) are delivered at different sites along the apical dendrite. We show that the boosting of firing dips in the middle dendritic segments as a result of increased $I_{\mathrm{h}}$ density but increases again in the distal dendrites as $\mathrm{Ca}^{2+}$-mediated bursts are triggered. Second, we examine the relationship between burst characteristics and the input barrages delivered to the distal apical dendrite. It is still unclear whether there is a tight coupling between stimulus and bursting, a property that would permit encoding a large input parameter space. We show that the bursting pattern changes systematically with the magnitude of the input barrages. These results indicate that input-output properties of pyramidal neurons vary both quantitatively and qualitatively with the location of the input and may 
therefore provide a substrate for a separate coding scheme in the distal dendrites.

\section{Materials and Methods}

Surgical and slicing techniques were used as described previously (Stuart and Sakmann, 1994) and followed guidelines set forth by the Animal Welfare Committee of New York University. Wistar rats (3-5 weeks of age) were anesthetized with halothane and decapitated. One hemisphere of the brain was excised, glued to a slicing chamber, and immersed in ice-cold oxygenated artificial CSF (ACSF) (in mM: $125 \mathrm{NaCl}, 2.5 \mathrm{KCl}, 25$ glucose, $25 \mathrm{NaHCO}_{3}, 1.25 \mathrm{NaH}_{2} \mathrm{PO}_{4}, 2 \mathrm{CaCl}_{2}$, and $\left.1 \mathrm{MgCl}_{2}\right)$. A vibratome slicer was used to make parasagittal (300- $\mu \mathrm{m}$-thick) slices cut at a $15^{\circ}$ angle from the horizontal plane. The slices were stored in a holding chamber maintained at $34^{\circ} \mathrm{C}$ for $1 \mathrm{~h}$ and at room temperature thereafter. Individual slices were transferred to a recording chamber mounted on an upright microscope and perfused with ACSF heated to $33-34^{\circ} \mathrm{C}$. In some experiments, 4-( $N$-ethyl- $N$-phenylamino)-1,2-dimethyl-6-(methylamino) pyridinium chloride (ZD7288) (Tocris Cookson, Ballwin, MO) dissolved in ACSF to $50 \mu \mathrm{m}$ was used to block $I_{\mathrm{h}}$ (Berger et al., 2001). Layer 5 pyramidal neurons in sensorimotor cortex were visualized and identified using infrared, differential interference contrast videomicroscopy. Whole-cell currentclamp recordings were performed using borosilicate microelectrodes pulled to diameters of 2 and $1 \mu \mathrm{m}$ for somatic and dendritic recordings, respectively. Electrodes had DC resistances of 5-20 M $\Omega$ when filled with the following (in $\mathrm{mM}$ ): $100 \mathrm{~K}$-gluconate, $20 \mathrm{KCl}, 4 \mathrm{MgATP}, 10$ phosphocreatine, $0.3 \mathrm{GTP}$, and $10 \mathrm{HEPES}$. Voltage and current signals were filtered at $10 \mathrm{kHz}$ using Cornerstone BVC-700 amplifiers (Dagan Corporation, Minneapolis, $\mathrm{ME}$ ) and digitized at $2-10 \mathrm{kHz}$. Stimulus delivery and data acquisition and analyses were implemented in IGOR (Wavemetrics, Lake Oswego, OR).

Neurons were stimulated with inputs that mimic the composite synaptic current generated by the firing of a population of presynaptic excitatory neurons (see Fig. 1A) (Oviedo and Reyes, 2002). A computer program simulated the firing of a specified number of presynaptic cells $\left(N_{\text {pre }}\right)$ each firing at a specified rate $\left(F_{\text {pre }}\right)$. The total incoming EPSC rate is equal to $N_{\text {pre }}{ }^{\star} F_{\text {pre. }}$. Jitter was added to the interspike intervals (ISIs) of each spike train such that the ISIs were distributed normally about a mean interval with SD $\pm 10 \%$ of the ISI. The start times of the spike trains were uniformly distributed within one ISI so that the simulated spike trains were uncorrelated.

Each time a simulated presynaptic cell fired an action potential (AP), a single EPSC was calculated. The time course of each EPSC (see Fig. $1 B$ ) was described by $I(t)=k\left(1-e^{-t / \tau 0}\right) e^{-t / \tau 1}$, where $k$ determines the amplitude of the synaptic input, and $\tau_{0}$ and $\tau_{1}$ are time constants describing the rise and fall times of the postsynaptic current, respectively. When injected into a cell, a transient voltage deflection was evoked; the amplitude and time course were adjusted to match those of unitary EPSPs measured with paired recordings (amplitudes, 0.4-1.0 mV) (Reyes and Sakmann, 1999). The EPSCs injected into the dendrite $\left(\right.$ EPSC $_{\mathrm{d} 1}$ and EPSC $_{\mathrm{d}_{2}}$ ) were adjusted so that resultant single EPSPs at the soma $\left(\right.$ EPSP $_{\mathrm{d} 1 \rightarrow \mathrm{S}}$, EPSP $_{\mathrm{d} 2 \rightarrow \mathrm{S}}$ ) had the same amplitudes and time courses. To mimic a barrage of EPSCs, the unitary EPSCs were convolved with the spike trains of the simulated presynaptic cells (Reyes et al., 1996; Oviedo and Reyes, 2002). The current trains from all of the presynaptic cells were summed, converted to an analog signal, and injected into the cell via the amplifier and recording electrode (see Fig. $1 \mathrm{~A}$ ). Stimuli were $1.2 \mathrm{~s}$ long and delivered at $>3 \mathrm{~s}$ intervals to ensure that the cells reached resting conditions between each stimulus. Some recordings were performed under dynamic clamp, a voltage-controlled current clamp that uses an analog multiplier to calculate and inject the current that would be produced by conductance changes (Robinson and Kawai, 1993; Sharp et al., 1993). One electrode was used for current injection and the other to record the membrane potential (Chance et al., 2002). Excitatory currents were calculated as $I_{\text {syn }}=g_{\text {syn }}\left(E_{\text {rev }}-V\right)$, where $g_{\text {syn }}$ is the computer-controlled synaptic conductance generated from the simulated presynaptic spike trains, $E_{\mathrm{rev}}$ is the reversal potential of the synaptic conductance $(0 \mathrm{mV}$ for excitatory inputs), and $V$ is the membrane potential.

\section{Results}

We performed simultaneous whole-cell recordings at the soma and at two sites in the apical dendrite of layer 5 pyramidal neurons $(n=40)$. We injected stimuli that mimicked barrages of synaptic inputs that would be generated in a neuron when a population of presynaptic cells fire repetitively (see Materials and Methods). These barrages were delivered through electrodes placed in the proximal $\left(\mathrm{d}_{1}, 77-163 \mu \mathrm{m}\right.$; mean, $\left.109 \pm 33.2 \mu \mathrm{m}\right)$, middle $\left(\mathrm{d}_{2}, 200-334 \mu \mathrm{m}\right.$; mean, $\left.270 \pm 54 \mu \mathrm{m}\right)$, and distal $\left(\mathrm{d}_{3}\right.$, 400-600 $\mu \mathrm{m}$; mean, $500 \pm 62 \mu \mathrm{m}$ ) segments of the apical dendrite. To assess the effectiveness of inputs (i.e., the degree of boosting) in the different compartments, the somatic responses to stimuli injected at the dendritic sites were compared with those obtained when stimuli were delivered directly at the soma.

\section{Boosting of inputs at proximal and middle dendritic sites}

The computer-generated inputs were first injected at dendritic locations $\mathrm{d}_{1}$ and $\mathrm{d}_{2}$, and the associated subthreshold voltage responses were recorded at the soma. To facilitate comparison, the amplitudes of the simulated synaptic currents (which mimic unitary EPSCs) injected at $\mathrm{d}_{1}$ and $\mathrm{d}_{2}$ were adjusted so that the resultant voltage deflections (which resemble unitary EPSPs) recorded with the somatic electrode were nearly identical $\left(\operatorname{EPSP}_{\mathrm{d} 1 \rightarrow \mathrm{S}}\right.$, EPSP $_{\mathrm{d} 2 \rightarrow \mathrm{S}}$ ) (Figs. $1 \mathrm{~B}, 2 \mathrm{~A}$ ). To meet this condition, the EPSCs and EPSPs at $d_{2}$ were typically larger and narrower than those at $d_{1}$.

Although the individually injected EPSCs produced identical EPSPs at the soma (Fig. $2 \mathrm{~A}$, left), the responses to EPSC barrages delivered to $\mathrm{d}_{1}$ and $\mathrm{d}_{2}$ were significantly different from each other (right). The barrages were calculated by summing the synaptic inputs generated by a specified number $\left(N_{\text {pre }}\right)$ of simulated presynaptic cells, each of which fired randomly with respect to each other at a given frequency $\left(F_{\text {pre }}\right)$. These barrages resulted in noisy tonic depolarizations [composite EPSPs (cEPSPs)]. At low-EPSC rates $(0.04 \mathrm{kHz})$, the cEPSPs recorded at the soma with stimulation at $\mathrm{d}_{2}$ were only slightly smaller than those recorded with stimulation at $\mathrm{d}_{1}$ (Fig. $2 \mathrm{~B}$, left traces). This difference increased at higher EPSC rates (Fig. $2 B$, middle and right traces). A plot of the average cEPSP versus EPSC rate (Fig. $2 C$ ) shows that the difference continued to grow as the membrane potential approached threshold. The cEPSPs evoked with $d_{1}$ and $d_{2}$ stimulation were larger than those evoked by directly injecting the barrages at the soma $\left(\mathrm{cEPSP}_{\mathrm{S} \rightarrow \mathrm{S}}\right)$. The difference in the response between $\mathrm{d}_{1}$ and $\mathrm{d}_{2}$ stimulation was consistent across all neurons: a plot of $\mathrm{CEPSP}_{\mathrm{d} 2 \rightarrow \mathrm{S}}$ versus $\mathrm{CEPSP}_{\mathrm{d} 1 \rightarrow \mathrm{S}}$ for 10 cells shows that the points for large depolarizations were below the unity slope line (Fig. 2D).

To determine whether the subthreshold differences extended to the suprathreshold range, the EPSC rate was increased until the neuron fired repetitively. In general, a higher EPSC rate was needed to evoke firing with $d_{2}$ stimulation than with $d_{1}$ stimulation. Moreover, the firing frequency was consistently lower with $\mathrm{d}_{2}$ stimulation for the same EPSC rate (Fig. 3A, top and middle traces, $B)$. Both responses were significantly greater than those evoked with somatic injection (Fig. $3 A$, bottom) $(s \rightarrow s, n=7)$, indicating that inputs to both were boosted. Unlike subthreshold responses (Fig. 2C,D), the differences in firing rate between $d_{1}$ and $\mathrm{d}_{2}$ stimulation remained constant for the range of EPSC rates examined; the firing rate curves are vertically shifted from each other along the firing rate axis (Fig. $3 B)(n=14)$. A plot of the firing rates evoked with $\mathrm{d}_{2}$ stimulation versus those evoked with $d_{1}$ stimulation shows that approximately all of the points were below the unitary slope line (Fig. $3 C$ ). Pairwise comparison of the 


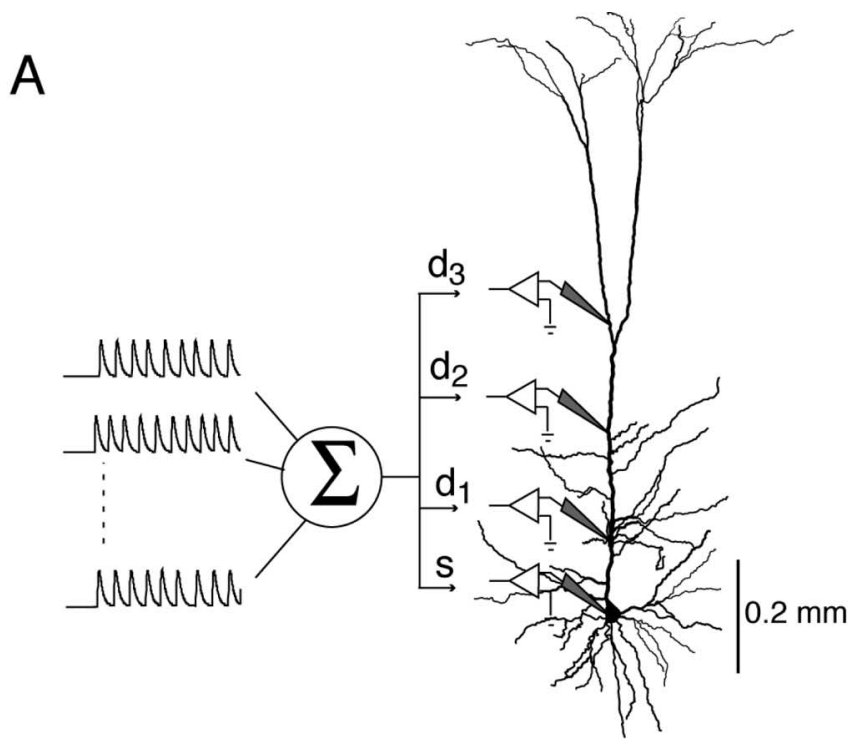

B
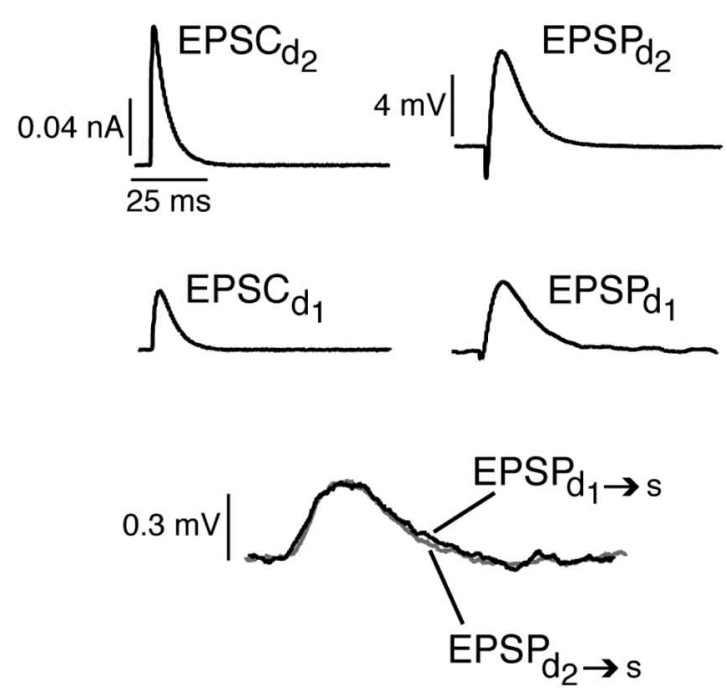

Figure 1. Stimulus protocol. $\boldsymbol{A}$, Trains of EPSCs generated by simulated presynaptic cells were summed and injected at the soma and at three locations in the apical dendrite (distance from soma): $d_{1}(77-163 \mu \mathrm{m}), d_{2}(200-334 \mu \mathrm{m})$, and $d_{3}(400-600 \mu \mathrm{m}) . B$, Individual EPSCs injected into dendritic locations $\mathrm{d}_{1}$ and $\mathrm{d}_{2}\left(\right.$ EPSC $_{\mathrm{d} 1}$ and EPSC $\mathrm{C}_{\mathrm{d} 2}$ ) and the resulting EPSPs recorded at each injection site (EPSP $\mathrm{d} 1, \operatorname{EPSP}_{\mathrm{d} 2}$ ) and at the soma (EPSP ${\mathrm{d} 1 \rightarrow \mathrm{s}^{\prime}} \operatorname{EPSP}_{\mathrm{d} 2 \rightarrow \mathrm{s}})$. In all of the experiments described in this study, the amplitude and time course of the individual EPSCS injected throughout the dendrite were adjusted to produce identical EPSPs at the soma.

firing rates evoked with $d_{1}$ and $d_{2}$ stimulation confirmed that the differences were significant ( $p=0.0001 ; n=14$; paired $t$ test).

\section{Boosting persists with dynamic-clamp stimulation}

The change in conductance caused by synaptic inputs can substantially alter the integrative properties of neurons. For excitatory synapses, increasingly larger membrane depolarizations decrease the excitatory drive effectively shunting the inputs. To determine whether boosting persists under this condition, the inputs were injected under dynamic clamp (see Materials and Methods). To accurately perform dynamic clamp (Prinz et al., 2004), two electrodes were placed in the dendrite (or soma) spaced $<10 \mu \mathrm{m}$ apart (Fig. $4 A$, inset). One electrode was used to inject current $(I)$, and the other was used to record the membrane potential $\left(V_{\mathrm{d}}\right)$. These two electrodes were placed at an average distance of $230 \mu \mathrm{m}( \pm 50 \mu \mathrm{m})$ from the soma. To monitor so-
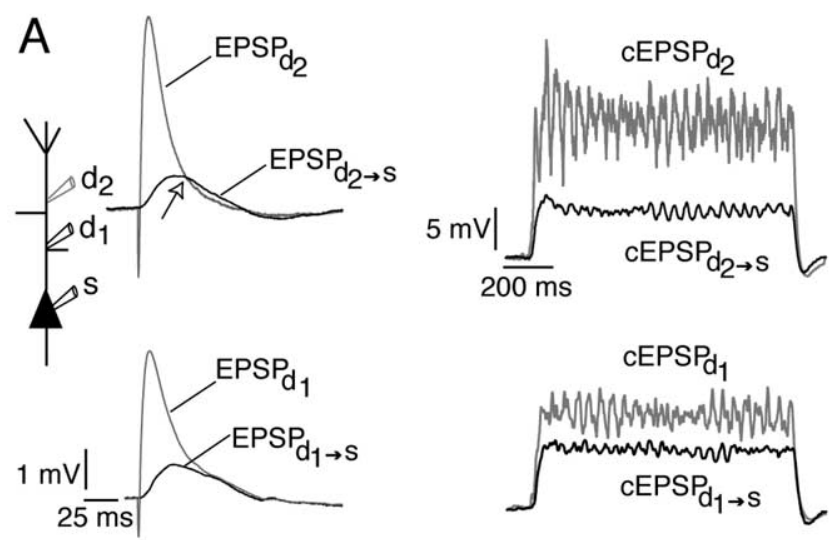

$B-c E P S P$
$-c E P S P$
$d_{1} \rightarrow S$

$0.24 \mathrm{kHz}$

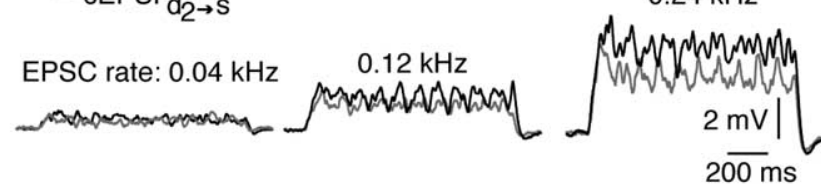

C
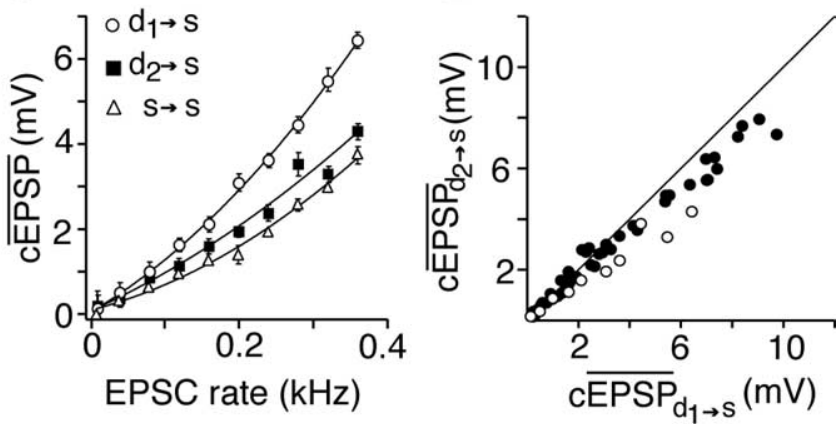

Figure 2. Subthreshold responses to proximal and middle dendritic stimulation. $\boldsymbol{A}$, Left, EPSPs recorded at the sites of injection $\left(\operatorname{EPSP}_{\mathrm{d} 1}, \mathrm{EPSP}_{\mathrm{d} 2}\right)$ and at the soma $\left(\operatorname{EPSP}_{\mathrm{d} 1 \rightarrow s^{\prime}}\right.$ $E P S P_{d 2 \rightarrow s}$ ). Electrodes at $d_{1}$ and $d_{2}$ were placed 150 and $334 \mu \mathrm{m}$, respectively, from the soma. The open arrow marks the crossover between EPSP ${ }_{\mathrm{d} 2}$ and EPSP $\mathrm{d} 2 \rightarrow \mathrm{s}_{\text {. Right, Depolarizations }}$ (CEPSPs) recorded at the dendrite $\left(\mathrm{CEPSP}_{\mathrm{d} 1}, \mathrm{CEPSP}_{\mathrm{d} 2}\right)$ and at the soma $\left(\mathrm{CEPSP}_{\mathrm{d} 1 \rightarrow \mathrm{s}^{\prime}} \mathrm{CEPSP}_{\mathrm{d} 2 \rightarrow \mathrm{s}}\right)$ when EPSC barrages (rate, $0.24 \mathrm{kHz}$ ) were injected at $\mathrm{d}_{1}$ or $\mathrm{d}_{2} . \boldsymbol{B}$, cEPSPs recorded at the soma in another neuron when stimuli of increasing EPSC rates were injected at $d_{1}$ (black; $185 \mu \mathrm{m}$ from the soma) and $d_{2}$ (gray; $300 \mu \mathrm{m}$ from the soma). C, Plot of average ( \pm SD) CEPSPs versus EPSC rate for barrages injected at $d_{1}$ (circles), $d_{2}$ (squares), and the soma (triangles) for the cell shown in $\boldsymbol{B}$. The curves are second-order polynomial fits to the data. $\boldsymbol{D}$, Plot of average $\mathrm{CEPSP}_{\mathrm{d} 2 \rightarrow \mathrm{s}}$ versus average EPSP $_{\mathrm{d} 1 \rightarrow \mathrm{s}}$ for 10 cells. The open circles are the data points shown in $\boldsymbol{C}$.

matic membrane potential $\left(V_{s}\right)$ during dynamic-clamp stimulation in the dendrite, a third recording electrode was placed at the soma.

As with current clamp, the cEPSPs evoked with dendritic stimulation were greater than those evoked with somatic stimulation (Fig. 4A, left), and this difference was significant (Fig. $4 A$, right) ( $p<0.001 ; n=5$; paired $t$ test). Likewise, suprathreshold dendritic stimulation evoked significantly $(p<0.0001 ; n=5$; paired $t$ test) higher firing rates than somatic stimulation (Fig. $4 B$ ). These results indicate that boosting would still occur in the presence of synaptic shunting.

\section{Effects of $I_{\mathrm{h}}$ blockade on boosting}

Two lines of evidence suggest that the decrease in boosting observed with stimulation of the middle dendritic segments was 
mediated by deactivation of the hyperpolarization-activated cation current, $I_{\mathrm{h}}$ (Williams and Stuart, 2000; Berger et al., 2001). First, the falling phase of $\operatorname{EPSP}_{\mathrm{d} 2}$ decayed faster than that of EPSP $_{\mathrm{d} 2 \rightarrow \mathrm{S}}$ so that the two waveforms crossed (Fig. $2 \mathrm{~A}$, open arrow, top left traces). The fact that crossing of the falling phases was not observed for injection at $\mathrm{d}_{1}$ (Fig. $2 \mathrm{~A}$, bottom left traces) is consistent with an increase in the density of $I_{\mathrm{h}}$ with distance from the soma (Stuart and Spruston, 1998; London et al., 1999). Second, the difference between $\mathrm{CEPSP}_{\mathrm{d} 2 \rightarrow \mathrm{S}}$ and $\mathrm{cEPSP}_{\mathrm{d} \mathrm{l} \rightarrow \mathrm{S}}$ often did not become apparent until $\sim 100$ ms after the stimulus onset, in the same range as the deactivation time constant of $I_{\mathrm{h}}$. To determine whether $I_{\mathrm{h}}$ does indeed contribute to the differences in the subthreshold and suprathreshold boosting between $\mathrm{d}_{1}$ and $\mathrm{d}_{2}$, the $I_{\mathrm{h}}$ channel blocker ZD7288 $(50 \mu \mathrm{M})$ was bath applied. During drug application, the resting membrane potential became more hyperpolarized $\left(\Delta V_{\mathrm{m}}\right.$, $10 \pm 1.5 \mathrm{mV} ; n=9)$, and the input resistance measured at the soma increased (control, $29 \pm 10 \mathrm{M} \Omega ; I_{\mathrm{h}}$ block, $58 \pm 12 \mathrm{M} \Omega ; n=9$ ). These effects are in line with $I_{\mathrm{h}}$ being tonically active at rest.

Consistent with previous results (Williams and Stuart, 2000), the width but not the rise time of individual EPSPs recorded at the soma following $\mathrm{d}_{1}$ and $\mathrm{d}_{2}$ stimulation increased in the presence of ZD7288 (Fig. 5A). This effect was magnified when a barrage of EPSCs were injected into the dendrite (Fig. 5B), similar to what was observed with trains of single EPSCs (Magee, 1999; Berger et al., 2001). In the presence of ZD7288, the differences in the subthreshold and suprathreshold responses between $d_{1}$ and $\mathrm{d}_{2}$ stimulation were eliminated (Fig. 5C,D). These results suggest that the differences in boosting were attributable to a higher density of $I_{\mathrm{h}}$ in the middle segment compared with the proximal segment; the differences in the responses cannot be simply accounted for by the passive filtering properties of the dendrites (Stuart and Spruston, 1998).

\section{Boosting in the distal dendrites}

Stimulation of the distal dendrites can trigger $\mathrm{Ca}^{2+}$-mediated bursts of APs and plateau potentials (Stuart et al., 1997; Larkum et al., 2001; Oakley et al., 2001; Larkum and Zhu, 2002). To assess the effects of these events on boosting, we recorded from the distal dendrites. As above, one electrode was placed at the soma and a second was placed at $d_{1}$. A third electrode $\left(d_{3}\right)$ was placed 400-600 $\mu \mathrm{m}$ from the soma. As observed for $\mathrm{d}_{2}$ stimulation, EPSCs delivered at low rates to $\mathrm{d}_{1}$ and $\mathrm{d}_{3}$ produced comparable depolarization at the soma. At higher EPSC rates, the responses to $\mathrm{d}_{3}$ stimulation were smaller than the responses to $\mathrm{d}_{1}$ stimulation (Fig. 6A), although the difference was not as large as that between $\mathrm{d}_{1}$ and $\mathrm{d}_{2}$ stimulation (see below). An additional increase in EPSC rate evoked firing (Fig. $6 \mathrm{~B}$ ); a higher EPSC rate was needed to induce firing with $d_{3}$ than with $d_{1}$ stimulation (Fig. 6C).

Consistent with previous results (Schwindt and Crill, 1999; Williams and Stuart, 1999; Zhu, 2000), d stimulation evoked mostly repetitive, single APs (Fig. $6 B$, left traces), whereas $d_{3}$
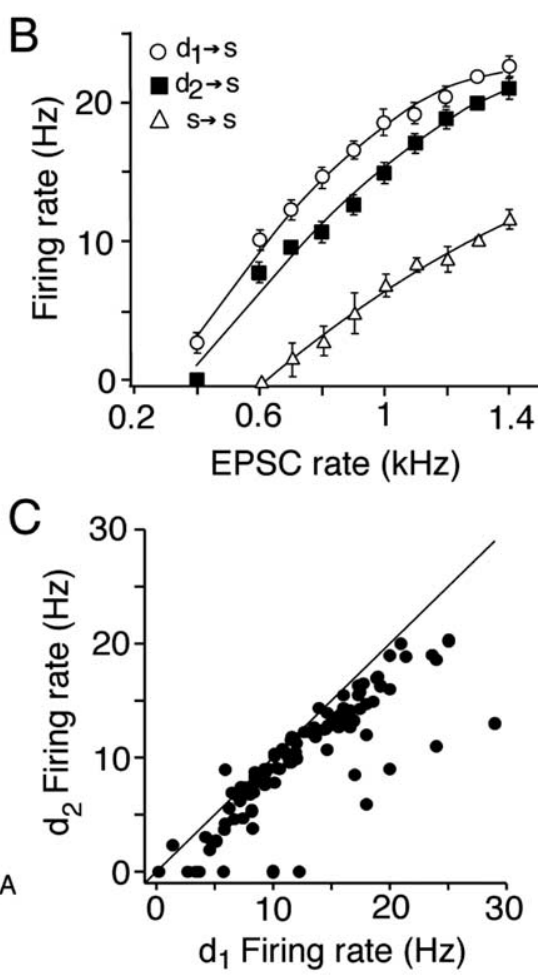

$\mathrm{d}_{2 \rightarrow \mathrm{s}}$

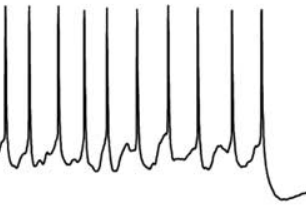

$\mathrm{d}_{1 \rightarrow \mathrm{s}}$

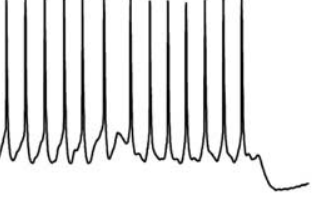

Figure 3. Boosting of firing rate in the middle and proximal dendritic segments. $A, A P$ trains recorded at the soma when EPSC ma (triangles). The curves are second-order polynomial fits to the data. $C$, Plot of average firing rate evoked with $d_{2}$ stimulation versus that evoked with $\mathrm{d}_{1}$ stimulation $(n=14)$.

stimulation evoked $\mathrm{Ca}^{2+}$-mediated complex spikes in the dendrites that resulted in bursts of APs at the soma (Fig. $6 \mathrm{~B}$, right traces). The presence of these $\mathrm{Ca}^{2+}$-mediated events compensated for the attenuating effects of $I_{\mathrm{h}}$. Unlike stimulating at $\mathrm{d}_{2}$, the low firing rates evoked with $\mathrm{d}_{3}$ stimulation (Fig. 6C, left) were equal to those evoked with $\mathrm{d}_{1}$ stimulation. At higher EPSC rates, however, there was an abrupt increase in the firing rate evoked with $d_{3}$ stimulation. The slopes of the relation for $d_{3}$ measured before and after the upward shift in firing rate were not significantly different ( $p=0.13 ; n=7$; paired $t$ test). A plot of the $\mathrm{d}_{3}$ firing rate versus $d_{1}$ firing rate for six cells shows that the increase in $\mathrm{d}_{3}$ boosting occurred when the firing rate was $>10 \mathrm{~Hz}$ (Fig. $6 \mathrm{C}$, right).

\section{Summary of boosting along the somatodendritic axis}

To document changes in boosting along the somatodendritic axis, the data were pooled as follows. In the experiments described above, three electrodes were placed on the neuron: one at the soma (s) and two at different sites on the dendrite. For comparison, the two dendritic sites are designated as $\mathrm{d}_{\mathrm{A}}$ (placed at the proximal dendrite) and $d_{B}$ (placed further from the soma anywhere from proximal to the distal dendrite). For both subthreshold $(n=15)$ and suprathreshold responses $(n=17)$, the percentage of boosting of inputs at the dendrite relative to the soma was calculated $\left[100 \times\left(R_{\mathrm{d}}-R_{\mathrm{s}}\right) / R_{\mathrm{s}}\right.$, where $R_{\mathrm{d}}$ and $R_{\mathrm{s}}$ are the dendritic and somatic responses, respectively, and can either be the average cEPSP or firing rate]. In the subthreshold range (Fig. $7 A$ ), when the second electrode $\left(\mathrm{d}_{\mathrm{B}}\right)$ was placed $<300 \mu \mathrm{m}$ from the soma (diamonds), the percentage of boosting was consistently less than that at $d_{A}$. The difference in boosting decreased when $d_{B}$ was 

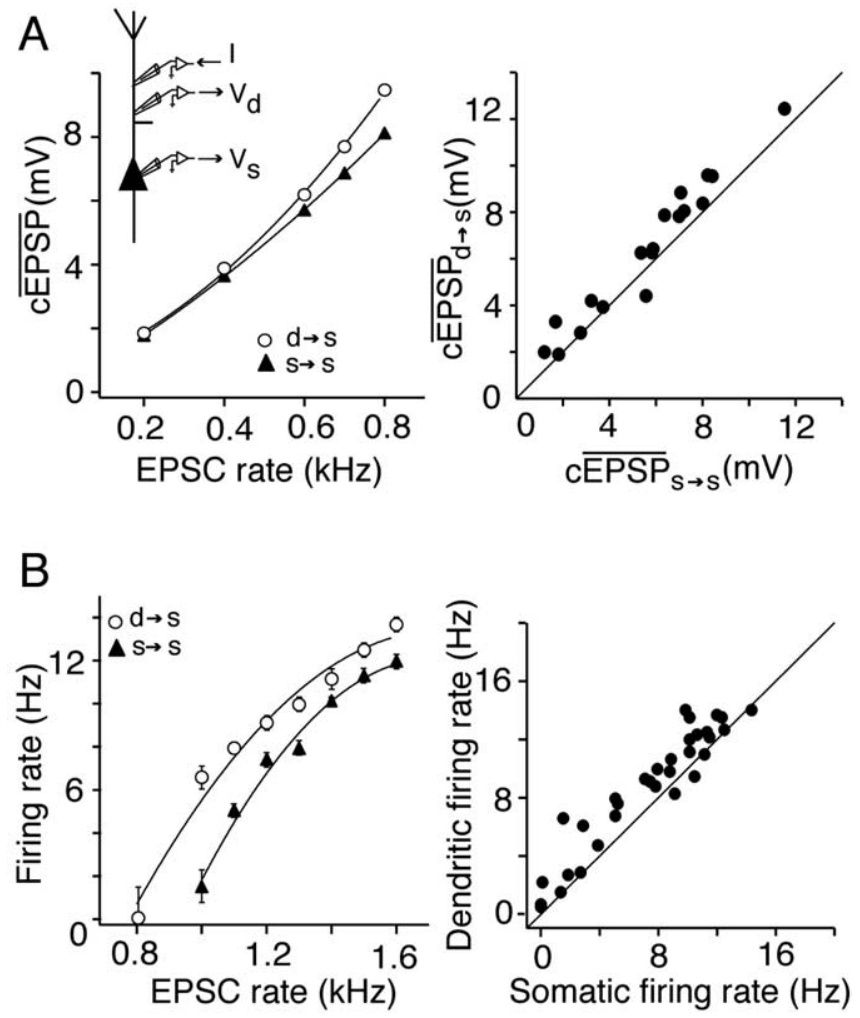

Figure 4. Boosting under dynamic clamp. $\boldsymbol{A}$, Left, Average cEPSPs recorded at the soma plotted against EPSC rate. EPSC barrages were injected either at the soma (triangles) or proximal dendrite (circles; $234 \mu \mathrm{m}$ from the soma) under dynamic clamp. The curves are secondorder polynomial fits to the data. Inset, Configuration for performing dynamic-clamp recordings in the dendrite. Two electrodes (spaced $<10 \mu \mathrm{m}$ apart) were placed in the apical dendrite. One electrode was used for injecting current $(I)$, and the other was used for recording voltage $\left(V_{d}\right)$. A third electrode was used to record membrane potential $\left(V_{s}\right)$ at the soma. For dynamic-clamp recording at the soma, the injecting and recording electrodes were placed on the cell body. Right, Plot of average somatic CEPSP evoked with dendritic stimulation versus the average somatic cEPSP evoked by direct stimulation of the soma $(n=5)$. $\boldsymbol{B}$, Left, Plot of average firing rate versus EPSC rate for the cell in $\boldsymbol{A}$ when inputs were injected either at the dendrite (circles) or at the soma (triangles). The curves are second-order polynomial fits to the data. Right, Plot of average firing rate for dendritic versus somatic stimulation.

placed at distances $>300 \mu \mathrm{m}$ (triangles). Similar relationships occurred in the suprathreshold range but were more exaggerated as the firing rates evoked at $\mathrm{d}_{\mathrm{B}}>300 \mu \mathrm{m}$ tended to exceed those evoked at $\mathrm{d}_{\mathrm{A}}$ (Fig. $7 B$ ). These trends can be seen more clearly by normalizing (dividing) the percentage of boosting at each dendritic site by the percentage of boosting at $\mathrm{d}_{\mathrm{A}}$ (Fig. 7C,D). A polynomial fit through each plot shows a dip in boosting at the middle dendritic segments followed by an increase at more distal sites. In the subthreshold range, the difference in the scaled boosting between middle and distal segments is less apparent than that in the suprathreshold range (Fig. $7 C, D$ ), although the differences were significant for both subthreshold and suprathreshold responses $(p<0.05 ; t$ test $)$.

\section{Variation of burst characteristics with input}

The bursting behavior evoked with $\mathrm{d}_{3}$ stimulation contrasted sharply with the predominantly repetitive single APs evoked with somatic, $d_{1}$, and $d_{2}$ stimulation. This suggests that inputs in the distal dendrites are encoded in a manner that is different from inputs near the soma. To assess the relationship between bursts and stimulus parameters, we documented changes in burst characteristics with the EPSC rate. A typical firing pattern evoked with
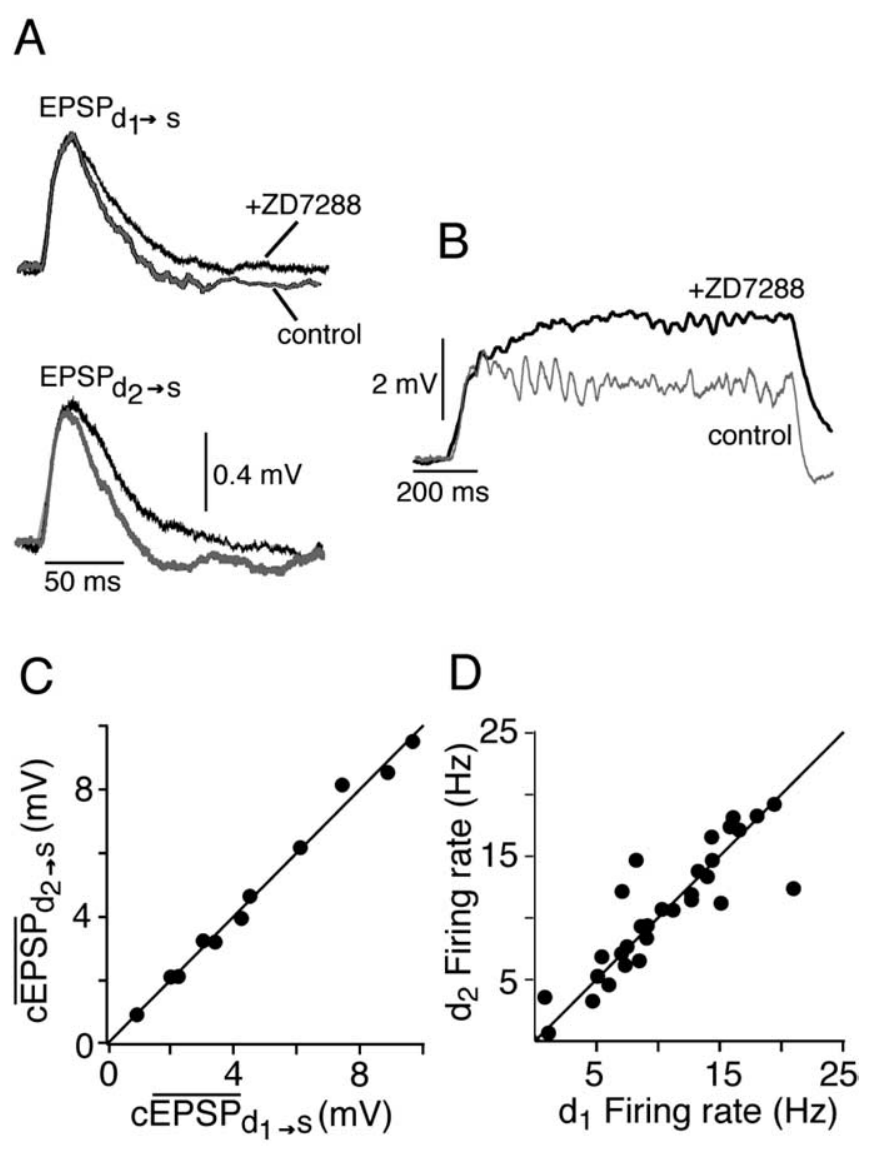

Figure 5. $I_{\mathrm{h}}$-mediated decrease in boosting. $A$, EPSPs recorded at the soma when single EPSCs were injected at $d_{1}$ (top; $185 \mu \mathrm{m}$ from the soma) and at $d_{2}$ (bottom; $350 \mu \mathrm{m}$ from the soma) under control conditions (gray traces) and in the presence of the $I_{\mathrm{h}}$ blocker $Z$ D7288 (black traces). $\boldsymbol{B}$, CEPSPs recorded at the soma when EPSC barrages were injected at $d_{2}$ under control (gray trace) and $I_{h}$-block (black trace) conditions. C, Plot of average CEPSP $_{\mathrm{d} 2 \rightarrow \mathrm{s}}$ versus average CEPSP $_{\mathrm{d} 1 \rightarrow \mathrm{s}}$ for five cells in the presence of ZD7288. $D$, Similar plot for average firing rates $(n=$ 6 cells).

$\mathrm{d}_{3}$ stimulation consisted of a burst of two to four high-frequency APs followed by a long interval (Fig. 8A) (see Fig. 10A). Histograms of ISI distribution compiled for a range of EPSC rates (Fig. 8 Aii) all show a peak at short ISIs; these correspond to the ISIs of APs in a burst (intraburst intervals). The intervals between the bursts (interburst intervals) were generally longer and are manifested as secondary peaks in the ISI histograms (Fig. 8 Aii, bottom histogram). APs were defined to occur in bursts if the ISIs were $<20 \mathrm{~ms}$ (APs in bursts can also be distinguished on the basis of their timing; see below). With $\mathrm{d}_{3}$ stimulation, bursting occurred consistently with EPSC rates as high as $1 \mathrm{kHz}$ (Fig. 8 Ai, Aii, bottom). In contrast, somatic or $\mathrm{d}_{1}$ stimulation evoked mainly repetitive APs with only occasional bursts at low EPSC rates (Fig. $8 \mathrm{~B}$ ). Bursting behavior is not restricted to a specific class of layer 5 pyramidal neurons. Both intrinsic bursting (IB) and regular spiking (RS) pyramidal neurons (classified by their responses to current steps delivered at the soma) (Connors et al., 1982; Chagnac-Amitai et al., 1990; Larkman and Mason, 1990; Wang and McCormick, 1993) exhibited bursting preferentially with distal dendritic stimulation. One difference was that bursting was evoked with stimulation at the soma and proximal dendrites in IB cells; but this occurred only at low EPSC rates (Fig. 8 B, left plots) (Williams and Stuart, 1999). Therefore, data from both cell types were pooled (Fig. $8 \mathrm{~B}$, right). 
A
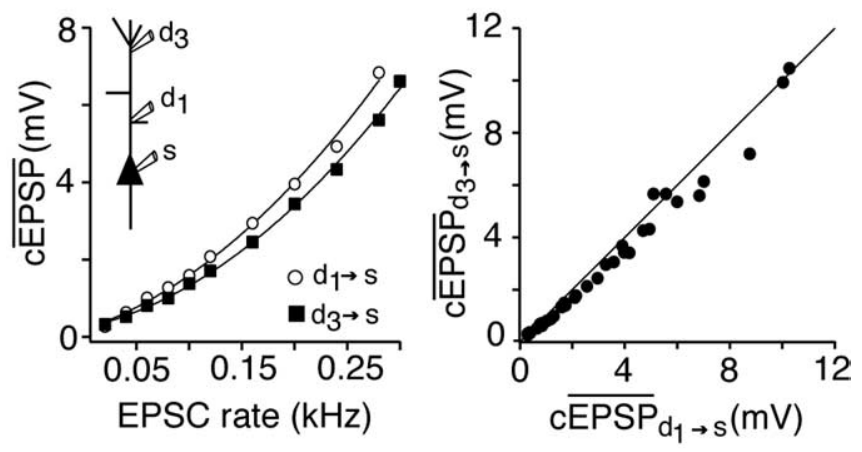

B EPSC rate: $0.28 \mathrm{kHz}$
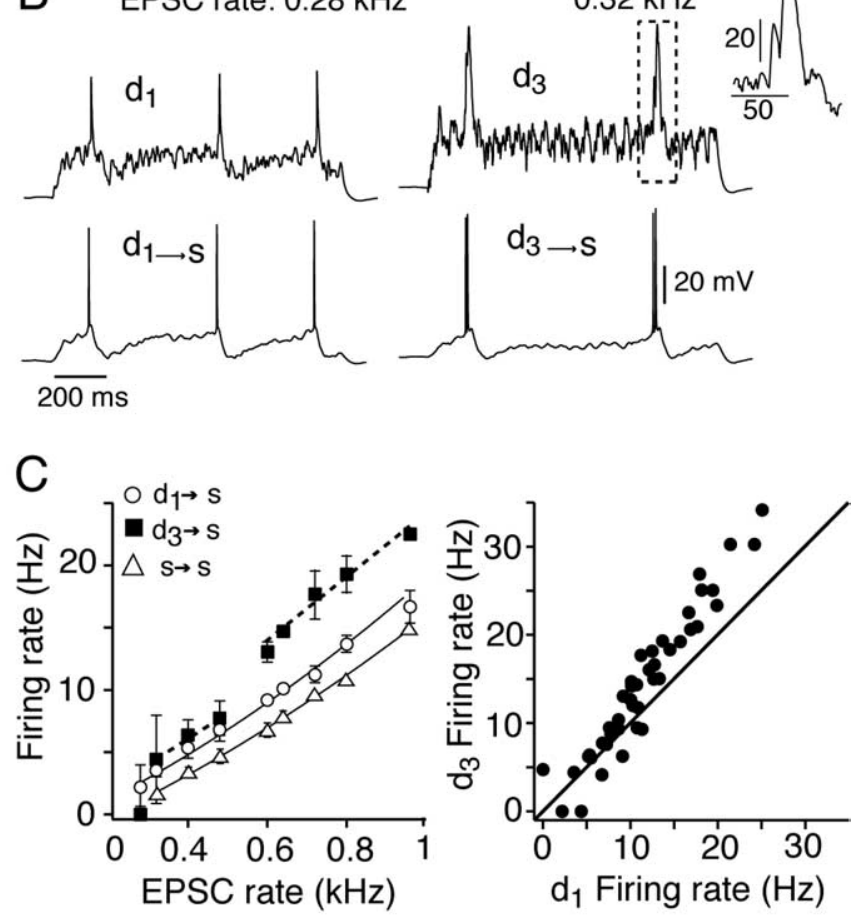

Figure 6. Boosting in the distal dendrite. $\boldsymbol{A}$, Left, Plot of average cEPSPs recorded at the soma versus EPSC rate when barrages were injected at $d_{1}$ (circles; $150 \mu \mathrm{m}$ from the soma) and at $d_{3}$ (squares; $550 \mu \mathrm{m}$ from the soma). The curves are second-order polynomial fits to the data. Right, Plot of average somatic cEPSPs evoked with $d_{3}$ stimulation versus those evoked with $d_{1}$ stimulation for six cells. $\boldsymbol{B}$, Left, Action potentials recorded at the dendrite (top) and soma (bottom) with just threshold stimulation at $d_{1}$. Right, Similar traces for stimulation at $d_{3}$. The complex spike recorded at $d_{3}$ (dashed box) is expanded in the inset. $\boldsymbol{C}$, Left, Average ( $\pm S D$ ) firing rate versus EPSC rate for the cell shown in $\boldsymbol{A}$ (left) and $\boldsymbol{B}$ when barrages were delivered at $d_{1}$ (circles), $d_{3}$ (squares), and soma (triangles). The solid curves are second-order polynomial fits to the $d_{1}$ and somatic data. The dashed lines on the $d_{3}$ data are linear fits before and after the step increase in firing rate. Right, Plot of average firing rate evoked with $d_{3}$ stimulation versus that evoked with $\mathrm{d}_{1}$ stimulation $(n=6)$.

There were systematic changes in the burst characteristics as the EPSC rate was increased. The intraburst intervals (Figs. $8 \mathrm{Ai}$, $9 A$ ) were shortest and the interburst intervals were longest at low EPSC rates (Figs. $8 A i, 9 B$ ). At progressively higher EPSC rates, the intraburst intervals increased, reaching maximum values just under $20 \mathrm{~ms}$ for an EPSC rate of $1 \mathrm{kHz}$ (Figs. 8Aii, 9A). The interburst intervals, in contrast, decreased (Fig. $9 B$ ). In general, the number of spikes in a burst was fairly constant, ranging from
A Subthreshold

B Suprathreshold
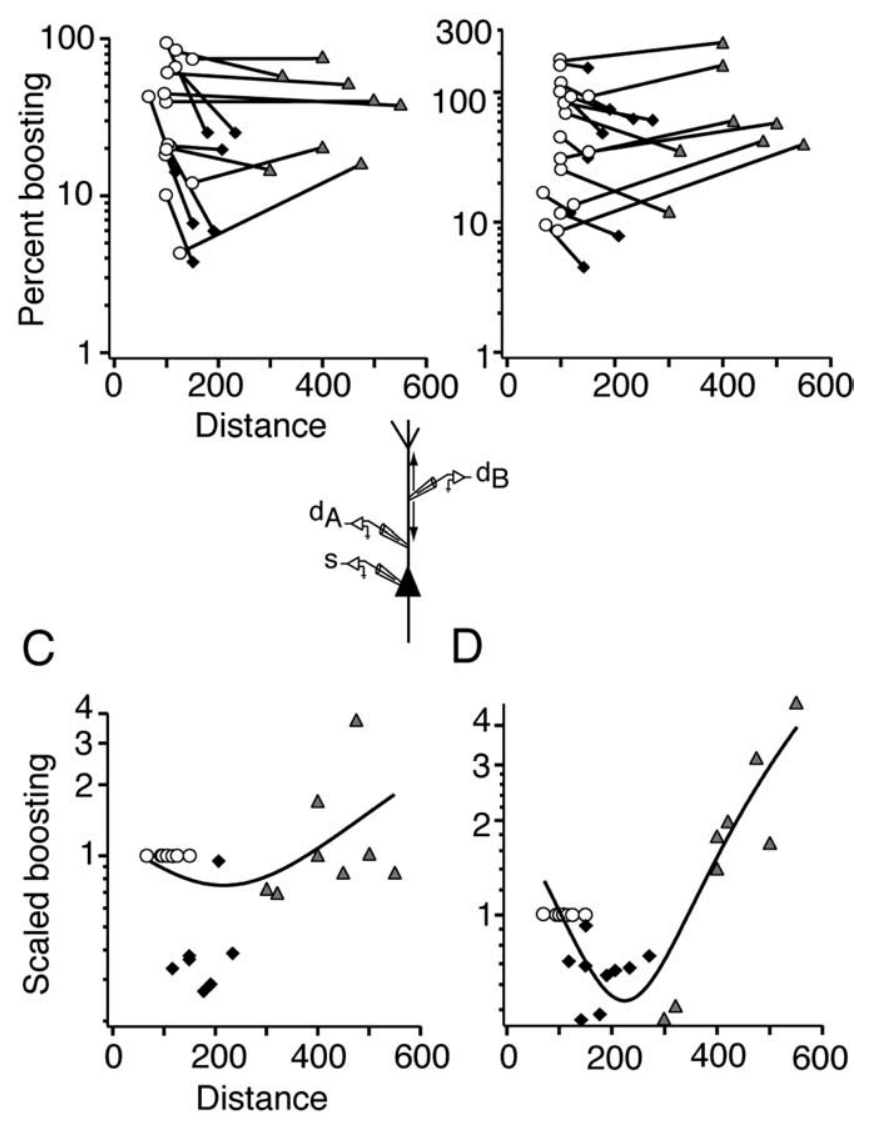

Figure 7. Summary of boosting along the somatodendritic axis. $A, B$, Plot of percentage of boosting (see Results) for subthreshold and suprathreshold responses versus the distance of the electrode from the soma. Inset, For each cell, two electrodes were placed in the dendrite, and a third was placed at the soma $(s)$. One dendritic electrode $\left(d_{A}\right)$ was placed at the proximal dendrite, and the other $\left(d_{B}\right)$ was placed at a site further from the soma anywhere from the proximal to the distal dendrite. Plots show the percentage of boosting for EPSC barrages delivered through electrode $d_{A}$ (circles) and for EPSC barrages delivered through electrode $d_{B}$ placed either at distances $<300 \mu \mathrm{m}$ (diamonds) or $>300 \mu \mathrm{m}$ (triangles) from the soma. The line connects points that were obtained from the same neuron. $\boldsymbol{C}, \boldsymbol{D}$, Data from $\boldsymbol{A}$ and $\boldsymbol{B}$ were normalized (divided) by the percentage of boosting at $d_{A}$. The curves are the best second-order polynomial fits to the data.

two to three APs per burst at all EPSC rates (Fig. 9C). Although the interburst and interspike intervals converged at high EPSC rates, the firing did not simply switch to repetitive firing mode as evidenced by two distinct peaks in the ISI distribution (Fig. 8 Aii) and by the timing of the APs.

With increasing EPSC rates, the bursting pattern became more complex, and the timing of the APs became more variable. To accurately document the changes in spiking patterns, we used the $C_{\mathrm{v} 2}$ metric $\left[2\left|\left(\Delta t_{\mathrm{i}+1}-\Delta t_{\mathrm{i}}\right)\right| /\left(\Delta t_{\mathrm{i}+1}+\Delta t_{\mathrm{i}}\right)\right]$, where $\Delta t$ is the ISI (Holt et al., 1996). Unlike the coefficient of variation $\left(C_{\mathrm{v}}\right)$, which gives the variance relative to the mean firing rate, $C_{\mathrm{v} 2}$ provides a measure of variability between pairs of adjacent ISIs during the stimulus and yields several values for a single-spike train. The importance of examining adjacent intervals for the duration of the stimulus is underscored by the fact that many neurons exhibit time-dependent adaptation in firing rate or fire bursts only near the onset of the stimulus. These nonstationary pro- 

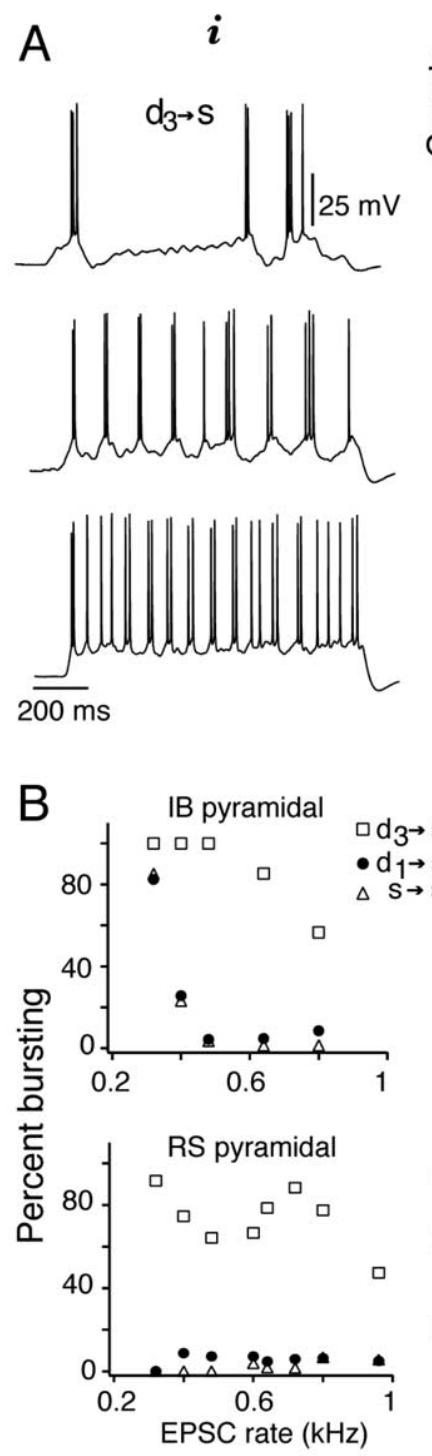
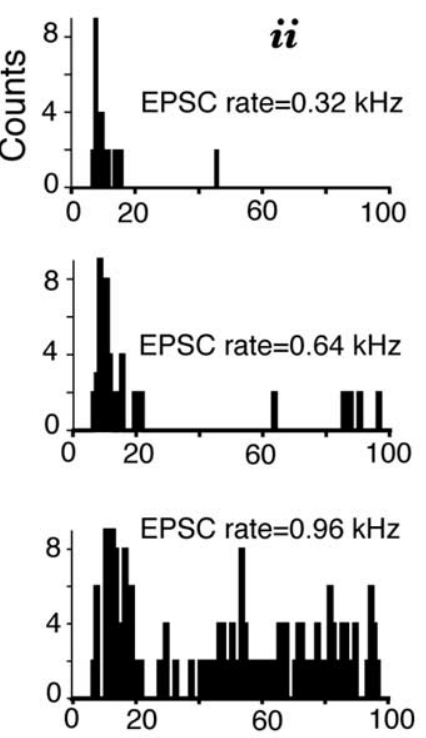

Interspike interval (ms)
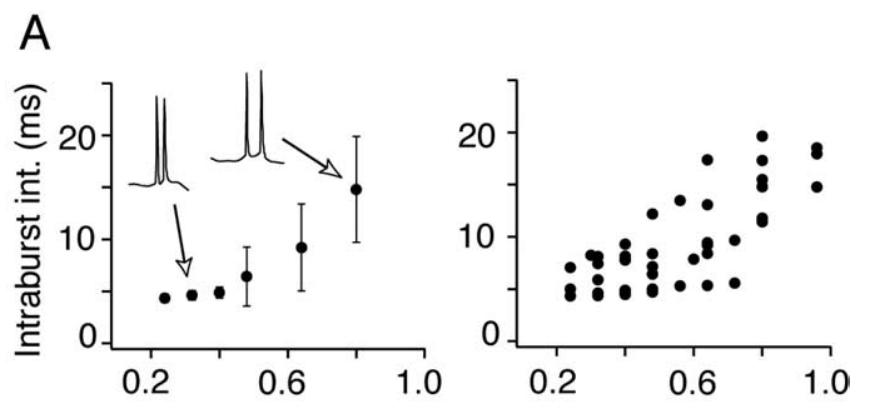

$\mathrm{B}$
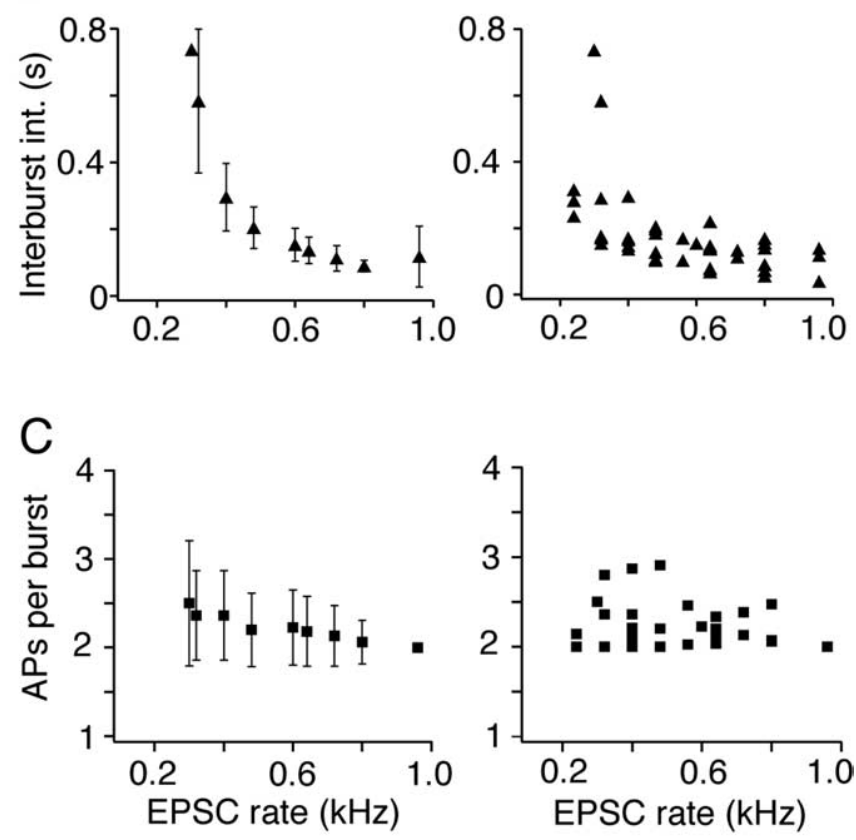

Figure 9. $A$, Average ( $\pm S D$ ) intraburst interval (int.) versus EPSC rate for one cell (left) and for six cells (right). Inset, Examples of APs that occurred in bursts. $\boldsymbol{B}$, Similar plots for the average $( \pm S D$ ) interburst interval (int.). $C$, Average ( \pm SD) number of APs in a burst versus EPSC rate.

Figure 8. Stimulus-dependent changes in burst characteristics. Ai, APs recorded at the soma when EPSC barrages were delivered at $d_{3}(550 \mu \mathrm{m}$ from the soma) at $0.32,0.64$, and $0.96 \mathrm{kHz}$. ii, Associated interspike interval histograms calculated from the AP trains. $\boldsymbol{B}$, Left, Percentage of APs that occurred in bursts as a function of EPSC rate when inputs were delivered at $d_{3}, d_{1}$, and the soma for an IB (top) and an RS (bottom) pyramidal neuron. Right, Similar plot for pooled data $(n=6)$.

cesses as well as the number of spikes within a burst are not readily discernable from ISI histograms or from the $C_{\mathrm{V}}$ metric. Details of the spiking patterns are revealed by plotting $C_{\mathrm{v} 2}$ for pairs of adjacent ISIs against the mean value of those two ISIs and examining the distribution of data points. Hence, neurons firing single action potentials at a regular rate $\left(\Delta t_{\mathrm{i}+1}=\Delta t_{\mathrm{i}}\right)$ yield $\sim 0$ $C_{\mathrm{V} 2}$ values that are tightly clustered. In contrast, highly variable spikes (large differences in $\Delta t_{\mathrm{i}+1}$ and $\Delta t_{\mathrm{i}}$ ), as would occur for a poisson process, yield a cloud of $C_{\mathrm{V} 2}$ values ranging from 0 to 2 that spans a wide range of mean ISI values. Changes in the spiking patterns are manifested as changes in the clustering patterns.

At low EPSC rates (Fig. 10 Ai, black dots), the repetitive bursts of two to three high-frequency APs resulted in two clusters of $C_{\mathrm{v} 2}$ values. One cluster at mean ISIs of $\sim 5 \mathrm{~ms}$ consisted of $C_{\mathrm{v} 2}$ values $<1$ and arose from three successive APs that occurred within bursts (the intraburst intervals were each $\leq 5 \mathrm{~ms}$ ). Another clus-

ter with high $C_{\mathrm{v} 2}$ values at mean ISIs of $\sim 150 \mathrm{~ms}$ arose from sequences consisting of three APs separated by an interburst $(\sim 300 \mathrm{~ms})$ and an intraburst $(\sim 5 \mathrm{~ms})$ interval. At a higher EPSC rate (Fig. 10 Aii), the firing switched to a very stereotyped, repetitive pattern consisting of a burst of two APs separated by a long and fixed interburst interval. The associated $C_{\mathrm{v} 2}$ plot has one cluster at a mean ISI of $\sim 50 \mathrm{~ms}$. At still higher EPSC rates, the spiking pattern became more irregular as both the interburst and intraburst intervals became more variable. The mean values of two adjacent ISIs were between $\sim 30$ and $40 \mathrm{~ms}$, indicating a relatively constant average firing rate, but the $C_{\mathrm{v} 2}$ values ranged from $\sim 0$ to $>1.5$ (Fig. 10 Aiv). Thus, there is a transition in the firing pattern that depends on the intensity of the stimulus: from regular bursts to more variable spike times. The change in firing patterns with EPSC rate was observed for the entire data set (Fig. $10 A$, gray dots). The $C_{\mathrm{v} 2}$ values for the firing evoked with stimulation of the soma, $\mathrm{d}_{1}$, or $\mathrm{d}_{2}$ were generally $<0.5(n=30$; see below). The ISI histograms at the bottom of Figure $10 \mathrm{~A}$ show the changes in the distribution of interspike intervals for the same cell highlighted in the $C_{\mathrm{v} 2}$ panels. Note that the histograms do not capture details in the variability of the spike patterns. For example, the histograms in Figure 10, $A i$ and $A i i$, are similar, 

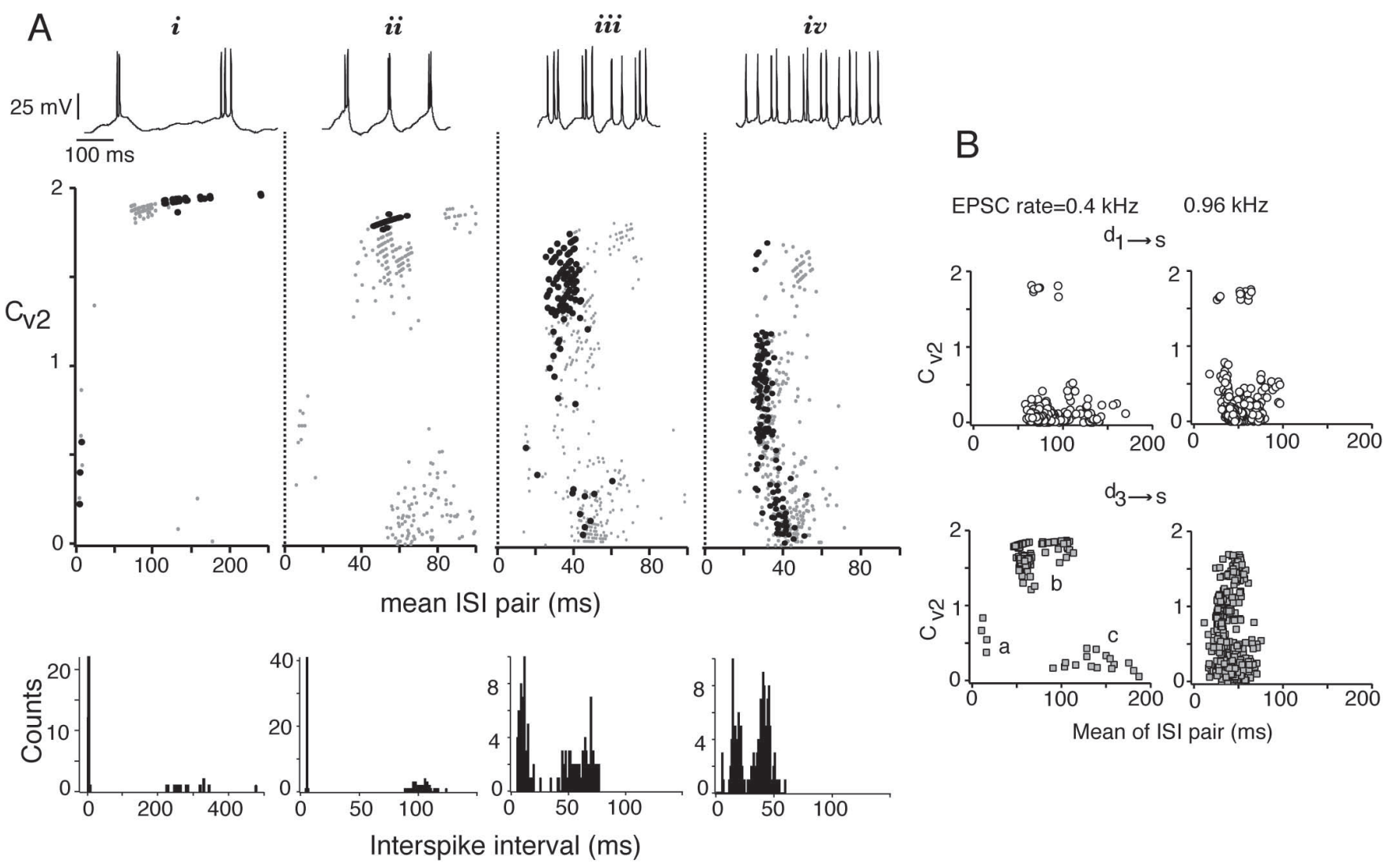

Figure 10. Variability of firing in the distal dendrites. $A$, Top, Voltage records of bursts evoked at different EPSC rates. Middle, $C_{\mathrm{v} 2}$ values of adjacent pairs of $I S I$ s plotted against the means of each ISI pair (see Results). $\boldsymbol{i}$ - $\boldsymbol{i v}$, Changes in the distribution of $\boldsymbol{C}_{\mathrm{v} 2}$ as a function of EPSC rate for one cell (black dots) and for six cells (gray dots). Bottom, ISI histograms for the cell highlighted in $\boldsymbol{A}$. $\boldsymbol{B}$, Plot of $\mathrm{C}_{\mathrm{v} 2}$ versus mean of ISI pair for $\mathrm{d}_{1}$ (top) and $\mathrm{d}_{3}$ (bottom) stimulation at two EPSC rates.

although the bursts consist of three and two spikes, respectively. Similarly, the higher variability of firing in Figure 10, Aiv compared with Aiii (top), is reflected in the spread of $C_{\mathrm{V} 2}$ values (iv, middle), whereas the histograms (bottom) are qualitatively similar.

The change in the distribution of $C_{\mathrm{v} 2}$ values with EPSC rates was not observed with stimulation of proximal dendrites (Fig. $10 \mathrm{~B})(n=7)$. At low EPSC rates $(0.4 \mathrm{kHz}), \mathrm{d}_{1}$ stimulation evoked mainly low-frequency $(\sim 10 \mathrm{~Hz})$, repetitive, single APs. The $C_{\mathrm{v} 2}$ values were generally $<0.5$ except for a few points that were attributable to occasional bursts at the start of the train. In contrast, the $C_{\mathrm{v} 2}$ values for $\mathrm{d}_{3}$ stimulation were in three clusters. One cluster (Fig. $10 B$, a) consisted of $C_{\mathrm{v} 2}$ values for sequences of three high-frequency APs that occurred in bursts. A second cluster (Fig. $10 \mathrm{~B}$, b) was from sequences of three APs separated by a long interval (interburst) and a short interval (intraburst). A third cluster (Fig. $10 \mathrm{~B}, \mathrm{c}$ ) was from sequences of three single APs that did not occur in bursts. Stimulation of $d_{1}$ at high EPSC rates $(0.96$ $\mathrm{kHz}$ ) increased the firing frequency of the neuron to $\sim 20 \mathrm{~Hz}$; the mean ISI pair values shifted leftward with only a slight increase in $C_{\mathrm{v} 2}$ values (Fig. $10 \mathrm{~B}$, right). For $\mathrm{d}_{3}$ stimulation, there was one cluster, but the range of $C_{\mathrm{v} 2}$ values ranged from $\sim 0$ to $>1.5$. This indicates that the bursting pattern evoked with $d_{3}$ stimulation persisted for a relatively large range of EPSC rates and firing frequencies and remained distinct from the repetitive APs evoked with $\mathrm{d}_{1}$ stimulation.

\section{Discussion}

The goal of this study was to document the input-output properties along the somatodendritic axis of pyramidal neurons. We examined whether boosting of inputs occurred along the entire length of the apical dendrite. Without boosting, inputs in the distal dendrites would be severely attenuated before reaching the spike initiation region (Stuart and Spruston, 1998). We showed previously that boosting of inputs in the proximal dendrites was mediated mainly by $\mathrm{Na}^{+}$conductances (Oviedo and Reyes, 2002). In this study, recordings were made at more distal sites to assess the contribution of other active conductances, which, unlike $\mathrm{Na}^{+}$conductances, may not be uniformly distributed in the dendritic tree. Furthermore, we characterize boosting for a variety of inputs, from single EPSPs to barrages that evoke repetitive firing. One important finding is that the degree of boosting varied along the somatodendritic axis. Boosting of both subthreshold and suprathreshold responses dipped in the middle (200-400 $\mu \mathrm{m})$ but increased in distal sites $(>400 \mu \mathrm{m})$ to equal or exceed boosting in the proximal dendrites $(<200 \mu \mathrm{m})$. Another important issue was how bursting evoked at the distal dendrites varied with input. The following two findings suggest that bursting is a viable means of encoding signals: (1) bursting persists under a wide range of input rates and remains distinct from repetitive APs, and (2) the burst characteristics change systematically with the input. The most prominent changes were an increase in the intraburst intervals, a decrease in the interburst intervals, and an 
increase in the variability of the AP times. This lends support for a separate integration site at the distal dendrites (Yuste et al., 1994; Williams and Stuart, 2003).

\section{Current clamp versus dynamic clamp}

The algorithm for calculating the input barrage sums the individual EPSCs linearly. Injecting these inputs into the cell under current clamp mimics the condition in which synaptic inputs from electrotonically and spatially distant branches converge at a common site (e.g., at the dendritic recording sites). Injecting the barrage under dynamic clamp simulates the case in which inputs are close to each other on the same branch. Under this condition, mutual shunting leads to sublinear summation (Rall, 1964). The fact that boosting occurred under both current-clamp and dynamic-clamp conditions suggests that the findings of this study can be generalized to a wide range of synaptic input configurations.

\section{$I_{\mathrm{h}}$-mediated decrease in boosting}

In the subthreshold range, the decrease in boosting observed at middle dendritic sites was likely a result of $I_{\mathrm{h}}$. Because $I_{\mathrm{h}}$ has a reversal potential of $-47 \mathrm{mV}$, it maintains the resting potential at a more depolarized level and decreases the input resistance of the cell. With depolarization, $I_{\mathrm{h}}$ deactivates within 20 to $100 \mathrm{~ms}$ (Berger et al., 2001) so that when the input barrage is injected, the resultant depolarization peaks but then decreases to a lower steady-state level (Fig. 2). The attenuating effects were greater at the middle dendritic segment, because the density of $I_{\mathrm{h}}$ increases with distance from the soma (Williams and Stuart, 2000; Berger et al., 2001). In the distal dendrite, the attenuating effects of $I_{\mathrm{h}}$ were partially counteracted by the presence of $\mathrm{Ca}^{2+}$ conductances (Figs. 6, 7). These $\mathrm{Ca}^{2+}$ conductances can be activated by single EPSPs and by subthreshold tonic depolarization (Schiller et al., 1997).

Similarly, boosting in the suprathreshold range dipped in the middle dendritic segments. During tonic repetitive firing, the associated depolarization deactivates $I_{\mathrm{h}}$, thereby reducing the net excitatory drive (Spain et al., 1987; Magee, 1999). Again, this effect is enhanced in middle dendritic sites because of the higher density of $I_{\mathrm{h}}$, although boosting is not completely eliminated.

In the proximal dendrite, $I_{\mathrm{h}}$ does not substantially reduce boosting of firing rate (compared with the soma). Previously, we showed that selectively blocking $\mathrm{Na}^{+}$channels in the proximal dendrite $(<200 \mu \mathrm{m})$ with tetrodotoxin caused the dendritically evoked firing to become equal, rather than dip below, to the somatically evoked firing (Oviedo and Reyes, 2002). This is consistent with the density of $I_{\mathrm{h}}$ being approximately equal in the soma and proximal dendrite (Berger et al., 2001).

Boosting in the distal dendrites was greatly magnified at high EPSC rates most likely because there was sufficient depolarization to trigger $\mathrm{Ca}^{2+}$ plateau potentials (Oakley et al., 2001; Larkum et al., 2004). The contribution of these $\mathrm{Ca}^{2+}$ plateau potentials is additive, shown by the upward shift in firing rate without an accompanying change in the slope of the input-output curve (Fig. 6C).

\section{Stimulus-dependent changes in bursting}

In addition to quantitative changes in firing rate along the somatodendritic axis, there were also prominent changes in the pattern of APs. In contrast to the soma and proximal dendritic sites, stimulation of distal dendrites evoked bursts. This bursting behavior has been documented both in vitro (Amitai et al., 1993; Kim and Connors, 1993; Markram and Sakmann, 1994; Yuste et al., 1994; Williams and Stuart, 1999) and in vivo (Larkum and
Zhu, 2002). We found that burst characteristics changed systematically with the EPSC rate. The increase in excitatory drive decreased the intervals between bursts but increased the intervals of APs within a burst. The latter is probably attributable to the accumulation of $\mathrm{Ca}^{2+}$ and an increase in the activation of $\mathrm{Ca}^{2+}$ dependent $\mathrm{K}^{+}$conductances (Yuste et al., 1994; Sah and Bekkers, 1996; Schiller et al., 1997; Schwindt and Crill, 1997; Helmchen et al., 1999). These $\mathrm{Ca}^{2+}$-dependent $\mathrm{K}^{+}$conductances have been implicated in regulating burst dynamics (Pinsky and Rinzel, 1994).

The changes in burst characteristics translated into an increase in the variability of firing. At low EPSC rates, the firing consisted mostly of repetitive bursts of two to three APs. At higher EPSC rates, the firing switched to bursts interspersed with single spikes, leading to more irregular firing. This indicates that although the highly irregular firing of cortical neurons can arise from synchronous synaptic drive (Softky and Koch, 1993; Stevens and Zador, 1998), $\mathrm{Ca}^{2+}$-mediated events in the distal dendrites may also contribute substantially to spike variability. A similar conclusion was reached by Larkum et al. (2004) with white noise current injection.

Burst characteristics (interburst intervals, intraburst intervals, and AP variability) changed systematically with EPSC rates. All three parameters did not saturate for EPSC rates as high as $1 \mathrm{kHz}$; at this input rate, the neuron can sustain tonic firing at frequencies ranging from 25 to $30 \mathrm{~Hz}$ for at least $1 \mathrm{~s}$. In the soma and proximal dendrites, the relationship between uncorrelated input and output can be described by a linear or sigmoidal function (Oviedo and Reyes, 2002). A similar relationship exists in the distal dendrite if the timing of APs is ignored and only the average firing rate is considered (Fig. 6C). However, bursting and repetitive APs are likely to have different effects on the postsynaptic target of the pyramidal neuron particularly because the majority of EPSPs evoked in target neurons exhibit depression or facilitation (Markram et al., 1998; Reyes et al., 1998; Reyes and Sakmann, 1999). Because the development and recovery from depression or facilitation depends on the intervals between APs, any change in the intervals between burst, intervals of APs within the burst, and the variability of the firing will lead to different amplitude EPSPs in the target neurons (Lisman, 1997; Tsodyks and Markram, 1997). In this view, four regularly spaced action potentials would have a different effect on the target cells than two action potentials occurring in two bursts (Lisman, 1997; Williams and Stuart, 1999). Thus, the information transmitted to target neurons by distal dendritic input may be fundamentally different from that transmitted by inputs near the soma even when the average firing rate of the pyramidal neuron is the same in both cases.

For simplicity, we used asynchronous inputs to drive the neurons. However, in vivo recordings reveal a wide range of synaptic input time courses. Because ionic conductances are time dependent, their activation states, and hence the evoked firing, are likely to change with the time course of inputs (Reyes, 2001). Additional experiments are needed to determine how, for example, synchronous inputs (Oviedo and Reyes, 2002) affect the bursting characteristics.

\section{Functional significance}

The apical dendrites of layer 5 pyramidal neurons can span nearly all of the cortical layers. The afferents from different classes of presynaptic cells are not scattered randomly throughout the dendritic tree but tend to be clustered on specific branches (Bernardo et al., 1990a,b; Ito, 1992; Gottlieb and Keller, 1997; Dodt et al., 
2003; Thomson and Bannister, 2003). The finding that boosting and firing patterns vary along the somatodendritic axis has several implications. First, inputs from different classes of presynaptic cells are boosted differentially. Afferents from other cortical areas and from layers $2 / 3$ that terminate in the distal apical dendrite would be weighted more than afferents that terminate in layer 4, near the middle dendritic segments. At the very least, greater boosting would partially compensate for the relatively smaller somatic EPSPs evoked with stimulation of distal dendrites (Williams and Stuart, 2002). Second, the different densities of active conductances would impart filtering characteristics to inputs at each dendritic segment. For example, the relatively slow kinetics of $I_{\mathrm{h}}$ deactivation would mean that tonic inputs would be preferentially attenuated over transient or synchronous inputs. Finally, qualitatively different firing patterns may provide a means of uniquely encoding inputs that occur in the distal dendrites. In this scenario, bursts would provide a "tag" for corticocortical signals, for example, that are processed in the distal dendrite.

\section{References}

Amitai Y, Friedman A, Connors BW, Gutnick MJ (1993) Regenerative activity in apical dendrites of pyramidal cells in neocortex. Cereb Cortex 3:26-38.

Bekkers JM (2000) Distribution and activation of voltage gated $\mathrm{K}^{+}$channels in cell-attached and outside-out patches from large L5 cortical pyramidal neurons of the rat. J Physiol (Lond) 525:611-620.

Berger T, Larkum ME, Lüscher H-R (2001) High $\mathrm{I}_{\mathrm{h}}$ channel density in the distal apical dendrite of L5 pyramidal cells increases bidirectional attenuation of EPSPs. J Neurophysiol 85:855-868.

Bernardo KL, McCasland JS, Woolsey TA, Strominger RN (1990a) Local intra- and interlaminar connections in mouse barrel cortex. J Comp Neurol 291:231-255.

Bernardo KL, McCasland JS, Woolsey TA (1990b) Local axonal trajectories in mouse barrel cortex. Exp Brain Res 82:247-253.

Chagnac-Amitai Y, Luhmann HJ, Prince DA (1990) Burst generating and regular spiking layer 5 pyramidal neurons of rat neocortex have different morphological features. J Comp Neurol 296:598-613.

Chance FS, Abbott LF, Reyes AD (2002) Gain modulation from background synaptic input. Neuron 35:773-782.

Connors BW, Gutnick MJ, Prince DA (1982) Electrophysiological properties of neocortical neurons in vitro. J Neurophysiol 48:1302-1320.

Dodt HU, Schierloh A, Eder M, Zieglgansberger W (2003) Circuitry of rat barrel cortex investigated by infrared-guided laser stimulation. NeuroReport 14:623-627.

Gabbiani F, Krapp HG, Koch C, Laurent G (2002) Multiplicative computation in a visual neuron sensitive to looming. Nature 420:320-324.

Gottlieb JP, Keller A (1997) Intrinsic circuitry and physiological properties of pyramidal neurons in rat barrel cortex. Exp Brain Res 115:47-60.

Häusser M, Major G, Stuart GJ (2001) Differential shunting of EPSPs by action potentials. Science 291:138-141.

Helmchen F, Svoboda K, Denk W, Tank DW (1999) In vivo dendritic calcium dynamics in deep-layer cortical pyramidal neurons. Nat Neurosci 2:989-996.

Holt GR, Softky WR, Koch C, Douglas RJ (1996) Comparison of discharge variability in vitro and in vivo in cat visual cortex neurons. J Neurophysiol 75:1806-1814.

Ito M (1992) Simultaneous visualization of cortical barrels and horseradish peroxidase-injected layer $5 \mathrm{~b}$ vibrissa neurones in the rat. J Physiol (Lond) 454:247-265.

Kim HG, Connors BW (1993) Apical dendrites of the neocortex: correlation between sodium- and calcium-dependent spiking and pyramidal cell morphology. J Neurosci 13:5301-5311.

Larkman A, Mason A (1990) Correlations between morphology and electrophysiology of pyramidal neurons in slices of rat visual cortex. I. Establishment of cell classes. J Neurosci 10:1407-1414.

Larkum ME, Zhu JJ (2002) Signaling of L1 and whisker-evoked calcium and sodium action potentials in distal and terminal dendrites of rat neocortical pyramidal neurons in vitro and in vivo. J Neurosci 22:6991-7005
Larkum ME, Zhu JJ, Sakmann B (2001) Dendritic mechanisms underlying the coupling with the axonal action potential initiation zone of adult rat L5 pyramidal neurons. J Physiol (Lond) 533:447-466.

Larkum ME, Senn W, Lüscher HR (2004) Top-down dendritic input increases the gain of layer 5 pyramidal neurons. Cereb Cortex 14:1059-1070.

Lisman JE (1997) Bursts as a unit of neural information: making unreliable synapses reliable. Trends Neurosci 20:38-43.

London M, Meunier C, Segev I (1999) Signal transfer in passive dendrites with nonuniform membrane conductance. J Neurosci 19:8219-8233.

Magee JC (1999) Dendritic $I_{h}$ normalizes temporal summation in hippocampal CA1 neurons. Nat Neurosci 2:508-514.

Markram H, Sakmann B (1994) Calcium transients in dendrites of neocortical neurons evoked by single subthreshold excitatory postsynaptic potentials via low-voltage-activated calcium channels. Proc Natl Acad Sci USA 91:5207-5211.

Markram H, Wang Y, Tsodyks M (1998) Differential signaling via the same axon of neocortical pyramidal neurons. Proc Natl Acad Sci USA 95:5323-5328.

Mel BW, Ruderman DL, Archie KA (1998) Translation invariant orientation tuning in visual "complex" cells could derive from intradendritic computations. J Neurosci 18:4325-4334.

Oakley JC, Schwindt PC, Crill WE (2001) Dendritic calcium spikes in layer 5 pyramidal neurons amplify and limit transmission of ligand-gated dendritic current to soma. J Neurophysiol 86:514-527.

Oviedo H, Reyes AD (2002) Boosting of neuronal firing evoked with asynchronous and synchronous inputs to the dendrite. Nat Neurosci 5:261-266.

Pinsky P, Rinzel J (1994) Intrinsic and network rhythmogenesis in a reduced Traub model for CA3 neurons. J Comput Neurosci 1:39-60.

Prinz AA, Abbott LF, Marder E (2004) The dynamic clamp comes of age. Trends Neurosci 27:218-224.

Rall W (1964) Theoretical significance of dendritic trees for neuronal inputoutput relations. In: Neural theory of modeling (Reiss RF, ed), pp 73-97. Palo Alto, CA: Stanford UP.

Reyes A (2001) Influence of dendritic conductances on the input-output properties of neurons. Annu Rev Neurosci 24:653-675.

Reyes A, Sakmann B (1999) Developmental switch in the short-term modification of unitary EPSPs evoked in layer 2/3 and layer 5 pyramidal neurons of rat neocortex. J Neurosci 19:3827-3835.

Reyes AD, Rubel EW, Spain WJ (1996) In vitro analysis of optimal stimuli for phase-locking and time-delayed modulation of firing in avian nucleus laminaris neurons. J Neurosci 16:993-1007.

Reyes AD, Lujan R, Rozov A, Burnashev N, Sakmann B (1998) Target cell specific facilitation and depression in neocortical circuits. Nat Neurosci 1:279-285.

Robinson HP, Kawai N (1993) Injection of digitally synthesized synaptic conductance transients to measure the integrative properties of neurons. J Neurosci Methods 49:157-165.

Sah P, Bekkers JM (1996) Apical dendritic location of slow afterhyperpolarization current in hippocampal pyramidal neurons: implications for the integration of long-term potentiation. J Neurosci 16:4537-4542.

Schiller J, Schiller Y, Stuart GJ, Sakmann B (1997) Calcium action potentials restricted to distal apical dendrites of rat neocortical pyramidal neurons. J Physiol (Lond) 505:605-616.

Schwindt PC, Crill WE (1997) Modification of current transmitted from apical dendrite to soma by blockade of voltage- and $\mathrm{Ca}^{2+}$-dependent conductances in rat neocortical pyramidal neurons. J Neurophysiol 78:187-198.

Schwindt PC, Crill WE (1999) Mechanisms underlying burst and regular spiking evoked by dendritic depolarization in layer 5 cortical pyramidal neurons. J Neurophysiol 81:1341-1854.

Sharp AA, O’Neil MB, Abbott LF, Marder E (1993) Dynamic clamp: computer-generated conductances in real neurons. J Neurophysiol 69:992-995.

Softky WR, Koch C (1993) The highly irregular firing of cortical cells is inconsistent with temporal integration of random EPSPs. J Neurosci 13:334-350.

Spain WJ, Schwindt PC, Crill WE (1987) Anomalous rectification in neurons from cat sensorimotor cortex in vitro. J Neurophysiol 57:1555-1576.

Stevens CF, Zador AM (1998) Input synchrony and the irregular firing of cortical neurons. Nat Neurosci 1:210-217. 
Stuart GJ, Sakmann B (1994) Active propagation of somatic action potentials into neocortical pyramidal cell dendrites. Nature 367:69-72.

Stuart GJ, Spruston N (1998) Determinants of voltage attenuation in neocortical pyramidal neuron dendrites. J Neurosci 18:3501-3510.

Stuart GJ, Schiller J, Sakmann B (1997) Action potential initiation and propagation in rat neocortical pyramidal neurons. J Physiol (Lond) 505:617-632.

Thomson AM, Bannister AP (2003) Interlaminar connections in the neocortex. Cereb Cortex 3:5-14.

Tsodyks MV, Markram H (1997) The neural code between neocortical pyramidal neurons depends on neurotransmitter release probability. Proc Natl Acad Sci USA 94:719-723.

Wang Z, McCormick DA (1993) Control of firing mode of corticotectal and corticopontine layer $\mathrm{V}$ burst-generating neurons by norepinephrine, acetylcholine, and 1S,3R-ACPD. J Neurosci 13:2199-2216.
Williams SR, Stuart GJ (1999) Mechanisms and consequences of action potential burst firing in rat neocortical pyramidal neurons. J Physiol (Lond) 521:467-482.

Williams SR, Stuart GJ (2000) Dendritic $\mathrm{I}_{\mathrm{h}}$ channels normalize EPSP time course. J Neurophysiol 83:3177-3182.

Williams SR, Stuart GJ (2002) Dependence of EPSP efficacy on synapse location in neocortical pyramidal neurons. Science 295:1907-1910.

Williams SR, Stuart GJ (2003) Role of dendritic synapse location in the control of action potential output. Trends Neurosci 26:147-154.

Yuste R, Gutnick MJ, Saar D, Delaney KR, Tank DW (1994) $\mathrm{Ca}^{2+}$ accumulations in dendrites of neocortical pyramidal neurons: an apical band and evidence for two functional compartments. Neuron 13:23-43.

Zhu JJ (2000) Maturation of layer 5 neocortical pyramidal neurons: amplifying salient layer 1 and layer 4 inputs by $\mathrm{Ca}^{2+}$ action potentials in adult rat tuft dendrites. J Physiol (Lond) 526:571-587. 